\title{
Knowledge, attitude and practice towards blood donation and associated factors among adults in Debre Markos town, Northwest Ethiopia
}

Yenework Acham Jemberu', Ahmed Esmael ${ }^{2+}$ and Kedir Y. Ahmed ${ }^{3 *+}$

\begin{abstract}
Background: Although the demand for blood supply has progressively increased in developing countries, evidences indicate that there is a major shortage of blood and blood products in these countries, particularly in Ethiopia. Thus, identifying motivational factors affecting blood donation and recruitment of safe and low risk donors is necessary. For this reason, the study aimed at assessing knowledge, attitude, and practice towards blood donation and its associated factors.

Methods: A community based cross-sectional study was conducted in Debre Markos town from February to April, 2015. Multi-stage sampling technique was employed to recruit a total of 845 study participants. Interviewer administered questionnaire was employed as a data collection tool. Binary logistic regression was applied to assess the relationship between explanatory variables and outcome variables.

Results: In this study, 436 (56.5 \%) and 403 (52.2\%) were found to be knowledgeable and having favorable attitude, respectively, while the other 124 (16.1\%) reported to have the practice of blood donation. Younger age group, male sex, those who attended formal education and radio listener were significantly associated with the knowledge of blood donation. Attending secondary and above education, having higher income, listening to radio broadcasts, and knowledge of blood donation were found to be the independent predictors of attitude. The practice of blood donation was higher among respondents who were older, attended certificate and above education, knowledgeable, and favorable attitude groups.

Conclusion: The prevalence of knowledge and practice of blood donation is found to be higher compared to similar study conducted in Mekelle, whereas the level of attitude is found to be lower. The finding of this study also justified any possible interventions on the independent predictors. There should be a regularly scheduled awareness creation and voluntary blood donation campaigns organized at the community level to utilize potential blood donors.
\end{abstract}

Keywords: Blood donation, Knowledge, Attitude, Practice

Abbreviations: AOR, Adjusted odds ratio; COR, Crude odds ratio; ERCS, Ethiopian Red Cross Society; KAP, Knowledge attitude and practice

\footnotetext{
* Correspondence: kedirymam331@gmail.com

${ }^{\dagger}$ Equal contributors

${ }^{3}$ Department of Public Health, College of Medicine and Health Science,

Debre Markos University, PO Box: 269, Debre Markos, Ethiopia

Full list of author information is available at the end of the article
} 


\section{Background}

Blood transfusion is a fundamental and a requisite part of any nation's health care delivery system for a lifesaving interventions. The need for blood and blood products is rising in all parts of the world [1, 2]. Evidence showed that about a quarter million maternal deaths globally and around $15 \%$ of child mortality in Africa were attributed to obstetric bleeding and anemia, respectively [3]. Had there been adequate and safe blood transfusion service such a significant mortality would have been averted. Globally, around 92 million unit blood donations are collected annually from all types of blood donors. The lowest levels of availability are found in low and middle income countries, particularly in Africa [2]. Blood donation rates in Africa is estimated to be 5/1000 populations compared with developed countries which is $47 / 1000$ population in USA [4].

Ethiopia is the second most populous nation in Africa, with an estimated population of 84 million [5]; a country with high MMR of 676/100,000 [6] and high motor vehicle accident (ranks $12^{\text {th }}$ in the world) [7] and with a larger non-immune population for malaria. The Ethiopian Red Cross Society (ERCS) has been the pioneer organization in developing blood banking services in the country. According to ERCS, the country's blood demand is estimated to be 80,000 to 120,000 units per year. However, only 24,000 units of blood were collected in 2004 (0.3 units/1000 people) and of these 17,000 units (71\% of the total) were collected from Addis Ababa. This figure indicates severe shortage of blood supply affecting the vast majority of the nation's population (about $96 \%)$ residing outside the capital city [8-10].

Therefore, improving the level of knowledge and hastening the development of positive attitude towards blood donation in the society should be the goal in designing an efficient strategy for sustaining a safe and adequate blood provision throughout the year. The first step to meet this goal should be performing an objective, thorough and comprehensive assessment of knowledge and attitude towards blood donation in the society. A study conducted in the city of Mekelle showed that half of the respondents have a low knowledge about blood donation. Only $10 \%$ have highly supportive attitude and majority (88 \%) did not have a history of blood donation [11]. This is lower than that of the study conducted among health science students in Addis Ababa. This study reported that the level of knowledge was $83 \%$ while $68 \%$ of students had favorable attitude, only $23.4 \%$ of them reported history of blood donation [12]. Occupational status, educational level, sex $[12,13]$, peer pressure, encouraging media and religion [14] were commonly reported independent predictors of KAP of blood donation.

Considering the magnitude and the gravity of the problem, finding few research papers in the area although might sound a little surprising. This makes research in the area profoundly pragmatic. The result of this study will be used in launching an appropriate motivational campaign in the field as there is no community based study conducted in Ethiopia. The aim of this study was thus to assess knowledge, attitude, and practice towards blood donation and its associated factors.

\section{Methods}

\section{Study design and study setting}

Community based cross-sectional study was conducted to assess the knowledge, attitude, and practice towards blood donation and its associated factors among adults in Debre Markos town from February to April 2015.

Debre Markos town is the capital city of East Gojam Zone. It is located $300 \mathrm{Km}$ from the capital of Ethiopia, Addis Ababa and $265 \mathrm{Km}$ from the Amhara Region capital, Bahir Dar. Based on Ethiopian population and housing census 2007 estimation, the total population of the town was estimated to be 101,582 , of which 52,827 of them were male [5].

\section{Source and study population}

All adults aged 18 to 65 years residing in Debre Markos town were the source population. Those adults who were selected by multi-stage sampling technique and lived in the study area for at least six months were included. Study participants who had serious illness during the data collection period and unable to hear were excluded from the study.

\section{Sample size determination}

The sample size was determined with a single population proportion formula by taking the prevalence rate of knowledge (49 \%) from the Mekelle study [11], which gives the largest sample size. Using $95 \% \mathrm{CI}$ and $5 \%$ margin of error, the sample size was found to be 845 after considering $10 \%$ non-response rate and design effect of two.

\section{Sampling techniques}

Multi-stage sampling technique was used to recruit the study participants. At stage one, three Kebeles (the lowest administrative unit in Ethiopia) were selected from the total of seven Kebeles of the town by lottery method. At stage two, systematic random sampling technique was used to select households with proportional allocation to the size of the kebeles. Finally, lottery method was employed to select one study participant for households with more than one eligible individual (aged 18-65 years old).

\section{Data collection}

Data were collected by face-to-face interview by using a structured and pre-tested questionnaire. The questionnaire was first prepared in English and translated to 
Amharic, then translated back to English by another person to check for its consistency. The questionnaire had five sections comprising; socio-demographic factors (age, sex, marital status, religion, monthly income, educational status and occupation), behavioral factors, knowledge questions (31 questions), attitude questions (12 questions) and practice questions (four questions) of blood donation. Seven diploma nurses and two BSc nurses were recruited as data collectors and supervisors, respectively.

\section{Data quality control}

The quality of data was assured by proper designing of the questionnaire and pre-testing of the questionnaire in one of the Kebeles other than the selected Kebeles. Training was given for the data collectors as well as supervisors by the principal investigator for a day just before and a day after the pretest. During the entire data collection days, all completed questionnaires were reviewed and cross-checked for completeness by the supervisors and all the necessary feedback was given to the data collectors immediately.

\section{Operational definitions}

Based on the mean score, those who score mean and above for knowledge questions were categorized as 'knowledgeable', otherwise 'not knowledgeable'. And those who score mean and above for attitude question were labeled as having 'favorable attitude', otherwise 'unfavorable attitude'. Regarding practice, having at least one history of blood donation was used to label them as having practice.

\section{Data processing and analysis}

All the questionnaires were checked visually, coded, and entered into EPI info version 6.0, then transferred to SPSS version 16.0 for analysis. Frequencies, proportions, and measures of central tendency and variation were used for descriptive analysis. Binary logistic regression analysis was used to examine association between the explanatory variables and dependant variables. All variables with $p$ value $<0.2$ in bivariate analysis were entered in to the final multiple logistic regression model to identify variables independently associated with KAP towards blood donation. Backward stepwise likelihood ratio was used to select the final independent predictors. The significance of Odds Ratio (OR) was declared at $p$ value $<0.05$.

\section{Ethical consideration}

This Study was reviewed and approved by the Ethical Review Committee of Debre Markos University, College of Medicine and Health Science. Formal permission letter was also obtained from concerned bodies of Debre Markos town. All participants were adequately pre-informed with regard to the aim and the implication of the study and were clearly told as to their full right to refuse or withdraw their verbal consent to participate in the research. Confidentiality of information were kept including omitting personal identifiers such as the name of the respondents.

\section{Result}

Socio-demographic characteristic of respondents

A total of 845 participants were sampled and 772 (91.4\%) of them were interviewed which yield a non-response rate of 73 (8.6\%). Among respondents, 426 (55.2\%) and $670(86.8 \%)$ of them were females and had primary school and above educational level, respectively. About $686(88.9 \%)$ of participants were Orthodox in religion and 389 (50.4) of them were married in marital status. Two hundred fifty two (32.6\%) of them were private workers, while the other 179 (23.2) of them were government employers (Table 1).

\section{Knowledge about blood donation and its associated factors}

All of the respondents were heard about blood donation at least once. The majority $601(71.2 \%)$ of which were heard from television followed by 92 (11.9\%), who were heard from radio. About 415 (53.8 \%) and 480 (62.2\%) of them knew that people can donate once in three months, and blood donation can be started at 18 years of age, respectively. Six hundred nine (78.9\%) of respondents knew that blood donation is beneficial for the donor's health. Majority, 746 (96.6\%) of respondents were reported that voluntary blood donation as the best source of blood supply and less than half (47\%) of them were aware of the risk of transmission of infection by blood transfusion. The risk of transmission of HIV, Hepatitis, Syphilis, and Malaria were mentioned by 46, 11.7, 12.2 and $6.1 \%$ of the respondents, respectively (Table 2). Considering 31 knowledge questions, 436 (56.5\%) of them scored mean and above indicates knowledgeable about blood donation.

The study showed that males $(\mathrm{AOR}=1.8995 \% \mathrm{CI}$ : $1.36,2.61)$ were more knowledgeable than females. Those who were at the age range of $18-25(\mathrm{AOR}=2.4295 \% \mathrm{CI}$ : $1.33,4.40)$ and $26-35(\mathrm{AOR}=2.0695 \% \mathrm{CI}: 1.13,3.73)$ years were more knowledgeable compared to reference age groups of 45 years and above. Being at primary school level $(\mathrm{AOR}=2.9395 \% \mathrm{CI}: 1.39,6.17)$, at secondary school level $(\mathrm{AOR}=3.3395 \% \mathrm{CI}: 1.68,6.60)$ and Certificate and above educational level $(\mathrm{AOR}=4.3995 \% \mathrm{CI}: 2.29,8.39)$ were significantly associated with knowledge of blood donation compared to those who have no formal education. The odds of being knowledgeable among radio broadcast listeners $(\mathrm{AOR}=0.3795 \% \mathrm{CI}=0.19,0.75)$ was significantly lower than internet and/or newspaper users (Table 3). 
Table 1 Socio demographic characteristics of respondents for the KAP of blood donation in Debre Markos town, Northwest Ethiopia, $2015(n=772)$

\begin{tabular}{|c|c|c|}
\hline Characteristics & Frequency & Percentage (\%) \\
\hline \multicolumn{3}{|l|}{ Age in years } \\
\hline $18-25$ & 292 & 37.8 \\
\hline $26-35$ & 235 & 30.4 \\
\hline $36-45$ & 130 & 16.8 \\
\hline$>45$ & 115 & 14.9 \\
\hline \multicolumn{3}{|l|}{ Sex } \\
\hline Male & 346 & 44.8 \\
\hline Female & 426 & 55.2 \\
\hline \multicolumn{3}{|l|}{ Religion } \\
\hline Orthodox & 686 & 88.9 \\
\hline Muslim & 68 & 8.8 \\
\hline Protestant/catholic & 18 & 2.3 \\
\hline \multicolumn{3}{|l|}{ Marital status } \\
\hline Married & 389 & 50.4 \\
\hline Single & 335 & 43.4 \\
\hline Widowed & 32 & 4.1 \\
\hline Divorced & 16 & 2.1 \\
\hline \multicolumn{3}{|l|}{ Educational status } \\
\hline No formal education & 102 & 13.2 \\
\hline Primary $\left(1-8^{\text {th }}\right)$ & 66 & 8.5 \\
\hline Secondary $\left(9-12^{\text {th }}\right)$ & 237 & 30.7 \\
\hline Certificate and above & 367 & 47.5 \\
\hline \multicolumn{3}{|l|}{ Occupational status } \\
\hline Private employer & 252 & 32.6 \\
\hline Government employer & 179 & 23.2 \\
\hline Student & 167 & 21.6 \\
\hline House wife & 138 & 17.9 \\
\hline Daily labor & 20 & 2.6 \\
\hline Other & 16 & 2.1 \\
\hline \multicolumn{3}{|l|}{ Monthly Income in Eth. Birr } \\
\hline$<500$ & 91 & 11.8 \\
\hline 500-1000 & 165 & 21.4 \\
\hline $1001-1500$ & 91 & 11.8 \\
\hline$>1500$ & 425 & 55.1 \\
\hline
\end{tabular}

\section{Attitude of blood donation and its associated factors} Among respondents, 598 (77.5\%) of them showed willingness to donate blood in the future. Of these, 571 (95.4\%) of them wanted to donate blood as voluntary donor and, the rest $25(4.3 \%)$ and $2(0.3 \%)$ of them as replacement and paid donors, respectively (Table 5). Regarding the composite measure of attitude, about 403 (52.2 \%) of the respondents had favorable attitude towards blood donation.
Table 2 Proportion of respondents who correctly answered knowledge questions among adults in Debre Markos town, Northwest Ethiopia, $2015(n=772)$

\begin{tabular}{|c|c|c|}
\hline Knowledge variables & Frequency & Percentage \\
\hline Knew place of blood donation & 685 & 88.7 \\
\hline Knew interval of blood donation & 415 & 53.8 \\
\hline Age to start blood donation & 480 & 62.2 \\
\hline \multicolumn{3}{|l|}{ Minimum criteria for blood donation } \\
\hline Age $18-65$ years & 286 & 37.0 \\
\hline weight above $45 \mathrm{~kg}$ & 231 & 29.9 \\
\hline Basic good health & 540 & 69.9 \\
\hline Blood donation is useful for donors health & 609 & 78.9 \\
\hline \multicolumn{3}{|l|}{ Importance of blood donation } \\
\hline Free health checkup & 107 & 13.9 \\
\hline Healthy feeling & 167 & 21.6 \\
\hline Feeling of happiness & 563 & 72.9 \\
\hline Reduction of heart attack & 55 & 7.1 \\
\hline Burns calories and control body weight & 34 & 4.4 \\
\hline Lower risk of cancer & 25 & 3.2 \\
\hline Best source of blood donation & 746 & 96.6 \\
\hline There is such thing as artificial blood & 521 & 67.5 \\
\hline \multicolumn{3}{|l|}{ Possible health risks of blood donation } \\
\hline Anemia & 251 & 32.5 \\
\hline Cross infection & 59 & 7.6 \\
\hline Fainting & 220 & 28.5 \\
\hline Sudden death & 32 & 4.1 \\
\hline HIV positive person can donate blood & 666 & 86.3 \\
\hline Knew any infections transmitted by transfusion & 363 & 47.0 \\
\hline \multicolumn{3}{|l|}{ Infection can transmit during blood transfusion } \\
\hline HIV/AIDS & 355 & 46.0 \\
\hline Hepatitis & 90 & 11.7 \\
\hline Syphilis & 94 & 12.2 \\
\hline Malaria & 47 & 6.1 \\
\hline \multicolumn{3}{|l|}{ Who are not eligible for blood donation } \\
\hline Infectious disease patients & 606 & 78.5 \\
\hline Pregnant and lactating women & 369 & 47.8 \\
\hline History of major surgery in past year & 190 & 24.6 \\
\hline History of blood transfusion & 119 & 15.4 \\
\hline Intra venous drug users & 53 & 6.9 \\
\hline
\end{tabular}

The likelihood of favorable attitude towards blood donation was higher among those who attended secondary school (AOR $=5.1595 \%$ CI: 2.81, 9.43) and certificate and above educational level (AOR $=4.8595 \% \mathrm{CI}: 2.70$, 8.72) compared to adults without formal education. The odds of favorable attitude was higher $(\mathrm{AOR}=1.8795 \% \mathrm{CI}$ : $1.13,3.09$ ) in 1500 Ethiopian Birr (ETB) and above monthly income groups. Radio listener had lower chance $(\mathrm{AOR}=$ 
Table 3 Factors associated with knowledge towards blood donation among adults in Debre Markos Town, Northwest Ethiopia $(n=772)$

\begin{tabular}{|c|c|c|c|c|}
\hline \multirow[t]{2}{*}{ Variables } & \multicolumn{2}{|c|}{ Knowledgeable } & \multirow[t]{2}{*}{ COR 95 \% Cl } & \multirow[t]{2}{*}{ AOR 95 \% Cl } \\
\hline & Yes & No & & \\
\hline \multicolumn{5}{|l|}{ Sex } \\
\hline Male & 229 & 281 & $2.07(1.55,2.78)$ & $1.89(1.36,2.61)^{* *}$ \\
\hline Female & 207 & 367 & 1 & 1 \\
\hline \multicolumn{5}{|l|}{ Age (years) } \\
\hline $18-25$ & 191 & 101 & $5.14(3.18,8.26)$ & $2.42(1.33,4.40)^{*}$ \\
\hline $26-35$ & 150 & 85 & $4.78(2.92,7.80)$ & $2.06(1.13,3.73)^{*}$ \\
\hline $36-45$ & 64 & 66 & $2.63(1.54,4.49)$ & $1.38(0.75,2.54)$ \\
\hline$>45$ & 31 & 84 & 1 & 1 \\
\hline \multicolumn{5}{|l|}{ Educational status } \\
\hline Non formal education & 18 & 84 & 1 & 1 \\
\hline Primary school $\left(1-8^{\text {th }}\right)$ & 30 & 36 & $3.89(1.93,7.85)$ & $2.93(1.39,6.17)^{*}$ \\
\hline Secondary $\left(9-12^{\text {th }}\right)$ & 147 & 90 & $7.62(4.30,13.5)$ & $3.33(1.68,6.60)^{* *}$ \\
\hline Certificate \& above & 241 & 126 & $8.93(5.14,15.5)$ & $4.39(2.29,8.39)^{* *}$ \\
\hline \multicolumn{5}{|l|}{ Source of information } \\
\hline Television & 355 & 246 & $0.64(0.38,1.07)$ & $1.03(0.60,1.76)$ \\
\hline Radio & 29 & 67 & $0.19(0.10,0.37)$ & $0.37(0.19,0.75)^{*}$ \\
\hline Newspaper/Internet & 52 & 23 & 1 & 1 \\
\hline
\end{tabular}

$C O R$, crude odds ratio, $A O R$ adjusted odds ratio

${ }^{* *} p$-value $<=0.001,{ }^{*} p$-value $<0.05$

Bold data indicates significant association

$0.4395 \%$ CI: $0.21,0.87)$ of having favorable attitude compared to newspaper and/or internet user. Being knowledgeable towards blood donation had increased (AOR $=1.4095 \%$ CI: 1.01, 1.94) odds of favorable attitude towards blood donation compared to its counterparts (Table 4).

\section{Practice of blood donation and its associated factors}

The practice of blood donation was found to be 124 (16.1\%) and of these, 79 (63.7\%) and 36 (29\%) of them were donated once, and twice, respectively. However, only $6(4.8 \%)$ of them were regular donors. Among those who ever donated blood, majority 79 (63.7 \%) of them were voluntary donors and, the remaining 45 (36.3\%) were donated to a friend or relative in need of blood. The reasons for non-donation were inability to think of it 219 (33.8\%), lack of opportunity 212 (32.7 \%), lack of time 72 (11.1\%), fear of pain 62 (9.6\%), fear of knowing their serostatus 9 (1.4\%) and non-remuneration 4 (0.6\%) (Table 5).

The likelihood of blood donation was higher among 18-25 years $(\mathrm{AOR}=0.4295 \% \mathrm{CI}: 0.19,0.92)$ and $26-35$ years $(\mathrm{AOR}=0.2695 \% \mathrm{CI}: 0.11,0.63)$ of age groups compared to the reference group of 45 and above year olds. Participants whose level of education was certificate and above were more likely $(\mathrm{AOR}=7.4095 \% \mathrm{CI}$ : $3.04,8.86)$ to donate blood compared to those who have no formal education. The odds of blood donation was found to be higher $(\mathrm{AOR}=3.1795 \% \mathrm{CI}: 1.90,5.28)$ among knowledgeable respondents compared to their counterparts. The odds of blood donation was 5.19 times (95 \% CI: 5.19 (3.04, 8.85)) higher among those with favorable attitude than unfavorable attitude (Table 6).

\section{Discussion}

The overall level of knowledge towards blood donation was found to be $56.5 \%$ which is higher than community based study conducted in the city of Mekelle (49\%) [11]. However, it is lower than another study conducted among health science students in Addis Ababa (83 \%) [12]. The difference in socio-economic status with residents of Mekelle and in educational status with the health science students might explain the discrepancy with the above findings. About $53.8 \%$ of participants knew that people can donate every 3 months, this is higher than other studies conducted in Benin, (21.5\%), Chennai (51.2\%) and Mekelle $(43.6 \%)[11,15,16]$. The majority of them reported voluntary blood donation as the best source of blood donation. This is consistent with finding from Chennai [16], however it is higher than studies conducted among health workers (72.2\%), and physicians in Benin (80.7\%) [15-17]. Less than half (47 \%) of adults knew the risk of transmission of disease through blood transfusion which is lower than that of the study conducted in Benin (95.7\%) [15] and, higher than that of the study conducted in India [18]. 
Table 4 Factors associated with attitude towards blood donation among adults in Debre Markos Town, Northwest Ethiopia $(n=772)$

\begin{tabular}{|c|c|c|c|c|}
\hline \multirow[t]{2}{*}{ Variables } & \multicolumn{2}{|l|}{ Attitude } & \multirow[t]{2}{*}{ COR 95 \% Cl } & \multirow[t]{2}{*}{ AOR $95 \%$ Cl } \\
\hline & Favorable & Unfavorable & & \\
\hline \multicolumn{5}{|l|}{ Educational status } \\
\hline Non formal education & 18 & 84 & 1 & 1 \\
\hline Primary school $\left(1-8^{\text {th }}\right)$ & 20 & 46 & $2.03(0.98,4.22)$ & $1.65(0.77,3.54)$ \\
\hline Secondary school $\left(9-12^{\text {th }}\right)$ & 140 & 97 & $6.74(3.81,11.92)$ & $5.15(2.81,9.43)^{* *}$ \\
\hline Certificate $\&$ above & 225 & 142 & $7.39(4.26,12.83)$ & $4.85(2.70,8.72)^{* *}$ \\
\hline \multicolumn{5}{|l|}{ Average Monthly Income } \\
\hline$<500$ Birr & 38 & 53 & 1 & 1 \\
\hline 500-1000 Birr & 66 & 99 & $0.93(0.55,1.56)$ & $0.87(0.5,1.53)$ \\
\hline 1000-1500 Birr & 28 & 63 & $0.62(0.34,1.14)$ & $0.52(0.27,0.99)$ \\
\hline$>1500$ Birr & 271 & 154 & $2.45(1.55,3.89)$ & $1.87(1.13,3.09)^{*}$ \\
\hline \multicolumn{5}{|l|}{ Use of media equipment } \\
\hline Television & 329 & 272 & $0.68(0.41,1.12)$ & $0.85(0.51,1.43)$ \\
\hline Radio & 48 & 27 & $0.21(0.11,0.40$ & $0.43(0.21,0.87)^{*}$ \\
\hline Newspaper/internet & 26 & 70 & 1 & 1 \\
\hline \multicolumn{5}{|l|}{ Knowledge } \\
\hline Knowledgeable & 171 & 265 & $2.23(1.66,2.97)$ & $1.40(1.01,1.94)^{*}$ \\
\hline Not knowledgeable & 198 & 138 & 1 & 1 \\
\hline
\end{tabular}

COR crude odds ratio, $A O R$ adjusted odds ratio

${ }^{* *} p$-value $<=0.001,{ }^{*} p$-value $<0.05$

Bold data indicates significant association

Age, sex, educational status and source of information were found to be independent predictors of knowledge of blood donation. Male study participants were more knowledgeable towards blood donation which is in line with findings from Karachi and North India $[19,20]$. In Ethiopian context, males are more accessible to information and spent most of their time out of their home than females. Having at least primary education was significantly and positively associated with the knowledge of blood donation, which is supported by a study conducted in Sikim, India [13]. This could be because more educated people might be in a better position to access the media and availability of awareness creation at primary and secondary school and higher educational institutions. Participants who used radio as a source of information were less knowledgeable than those who used newspaper and/or internet. This might be partly explained by the limitations of radio programs on addressing the intended goals. On the other hand the low level of knowledge found in a radio listeners might be due to their limited access, techno illiteracy and their limited educational preparedness to understand, analyze and absorb the content of the message.

The composite measure of attitude based on mean score indicates that $52.2 \%$ of the respondents had favorable attitudes towards blood donation. This is better than a study conducted in Karachi (42\%), however it is lower than similar studies conducted in India (87.3\%),
Mekelle (61 \%) and Addis Ababa (68 \%) [11, 12, 19, 21]. More than three-fourth of respondents had intention to donate blood in the future which is lower than other studies conducted in India (90\%) and Addis Ababa $(100 \%)[12,18]$. Studies conducted in India and Addis Ababa carried out among health science students showed that knowledge of blood donation was higher as a result of their profession.

The present study found that educational status, average monthly income, source of information, and knowledge were significantly associated with favorable attitude towards blood donation. Participants who had higher monthly income were more likely to have favorable attitude than lower income groups. This might be because those who have higher income may access better information sources. Radio listener had lower chance of having favorable attitude compared to newspaper reader and internet users. This might be partly explained by the limitations of radio programs on addressing the intended goals. On the other hand, the low level of knowledge found in a radio listeners might explain the unfavorable attitude of them as knowledge is an independent predictor of attitude.

In addition, about $16.1 \%$ of respondents reported at least one history of blood donation which is lower than similar studies conducted in Benin [15], Northern Nigeria [22], South India [21], and in Addis Ababa [12]. However, it is higher than other studies carried out in India (13.9 \%) 
Table 5 The intention and practice of blood donation among adults in Debre Markos Town, Northwest Ethiopia, $2015(n=772)$

\begin{tabular}{|c|c|c|}
\hline Variable & Frequency & Percentage \\
\hline \multicolumn{3}{|l|}{ History of blood donation } \\
\hline Yes & 124 & 16.1 \\
\hline No & 648 & 83.9 \\
\hline \multicolumn{3}{|l|}{ Frequency of donation } \\
\hline Once & 79 & 63.7 \\
\hline Twice & 36 & 29 \\
\hline Three times & 9 & 7.3 \\
\hline \multicolumn{3}{|l|}{ Type of blood donation } \\
\hline Voluntary & 79 & 63.7 \\
\hline Friends/relative & 45 & 36.3 \\
\hline \multicolumn{3}{|l|}{ Regular donors } \\
\hline Yes & 6 & 4.8 \\
\hline No & 118 & 95.2 \\
\hline \multicolumn{3}{|l|}{ Willingness in the future } \\
\hline Ye & 598 & 77.5 \\
\hline No & 174 & 22.5 \\
\hline \multicolumn{3}{|l|}{ Type of donation intended } \\
\hline Voluntary & 571 & 95.5 \\
\hline Replacement & 25 & 4.2 \\
\hline Paid & 2 & 0.3 \\
\hline \multicolumn{3}{|c|}{ Reasons of not blood donation } \\
\hline Didn't think of it & 219 & 33.8 \\
\hline Lack of opportunity & 212 & 32.7 \\
\hline Lack of time & 72 & 11.1 \\
\hline Fear of pain & 62 & 9.6 \\
\hline Fear knowing my status & 9 & 1.4 \\
\hline No remuneration & 4 & 0.6 \\
\hline Others & 70 & 10.8 \\
\hline
\end{tabular}

[18] and Mekelle (12\%) [11]. The difference in the practice of blood donation could be due to variation in the setup of study settings since some of the studies were conducted among health professionals and some others were at school level. Nearly two-third of blood donation were practiced as voluntary blood donation. This is supported by the study conducted in South India (64.1\%) [21]. About $4.8 \%$ of blood donors were regular donors, which is very low compared to similar study conducted in Benin (13.9\%) and facility based study from Addis Ababa $(42.2 \%)[12,15]$. The major reasons reported from those who didn't practice blood donation were inability to think of it (33.8\%), lack of opportunity to donate blood (32.7\%), and lack of time (11.1\%). Global researchers also concluded that people are not donating blood because nobody approached them for donation, lack of information, unfit to donate, a need to donate for a friend
Table 6 Factors associated with practice towards blood donation among adults in Debre Markos Town, Northwest Ethiopia $(n=772)$

\begin{tabular}{|c|c|c|c|c|}
\hline \multirow[t]{2}{*}{ Variables } & \multicolumn{2}{|c|}{ Practice } & \multirow{2}{*}{$\begin{array}{l}\text { COR with } \\
95 \% \mathrm{Cl}\end{array}$} & \multirow{2}{*}{$\begin{array}{l}\text { AOR with } \\
95 \% \mathrm{Cl}\end{array}$} \\
\hline & Yes & No & & \\
\hline \multicolumn{5}{|l|}{ Age (years) } \\
\hline $18-25$ & 39 & 253 & $1.11(0.58,2.14)$ & $0.27(0.11,0.65)^{*}$ \\
\hline $26-35$ & 39 & 196 & $1.44(0.75,2.77)$ & $0.26(0.11,0.63)^{*}$ \\
\hline $36-45$ & 32 & 98 & $2.36(1.19,4.68)$ & $0.79(0.33,1.94)$ \\
\hline$>45$ & 14 & 101 & 1 & 1 \\
\hline \multicolumn{5}{|l|}{ Educational status } \\
\hline Non formal education & 4 & 98 & 1 & 1 \\
\hline Primary school & 3 & 63 & $1.17(0.25,5.38)$ & $1.01(0.2,5.09)$ \\
\hline Secondary school & 21 & 216 & $2.38(0.80,7.12)$ & $2.08(0.58,7.42)$ \\
\hline Certificate and above & 96 & 271 & $8.68(3.11,24.23)$ & $7.40(3.04,8.86)^{* *}$ \\
\hline \multicolumn{5}{|l|}{ Knowledge } \\
\hline Knowledgeable & 100 & 336 & $3.87(2.42,6.20)$ & $3.17(1.90,5.28)^{* *}$ \\
\hline Not knowledgeable & 24 & 312 & 1 & 1 \\
\hline \multicolumn{5}{|l|}{ Attitude } \\
\hline Favorable & 104 & 299 & $6.07(3.67,10.04)$ & $5.19(3.04,8.85)^{* *}$ \\
\hline Unfavorable & 20 & 349 & 1 & 1 \\
\hline
\end{tabular}

COR crude odds ratio, $A O R$ adjusted odds ratio

** $p$-value $<=0.001,{ }^{*} p$-value $<0.05$

Bold data indicates significant association

or relative in future, fear of needle and knowing their viral status, the donated blood may be sold, non-remuneration, ignorance and their religion [12, 15, 17, 18, 21, 23].

Age, educational status, knowledge and attitude were significantly associated with the practice of blood donation. Older age groups were positively associated with the practice of blood donation. This is similar with findings from Karachi and Iran [21, 24]. This might be attributed to increased personal experience from donating blood. Having certificate and above educational level was associated with increased practice of blood donation which is comparable with the study carried out in Addis Ababa [12]. This might support the fact that education can positively influence the knowledge and attitudes of blood donation. In addition, being knowledgeable and having favorable attitude were found to be independent predictors of blood donation. Knowledge of blood donation is a pre-requisite in obtaining access to and providing voluntary blood donation timely and effectively. It is also an important tool in avoiding fear and building positive attitude of blood donors. This is supported by a similar study conducted in Mekelle [11].

The fact that this study was conducted at the community level could be mentioned as the strength of the study. The nature of cross-sectional study which is not possible to establish cause-effect relationship between the explanatory variables and outcome variables, and the possibility of social desirability bias were among the limitations of this study. 


\section{Conclusion}

The present study showed that the prevalence of knowledge and practice of blood donation is found to be higher compared to similar study conducted in Mekelle, whereas the level of attitude is found to be lower. Younger age group, male sex, who attended formal education and radio listener were significantly associated with knowledge of blood donation. Attending secondary and above education, having higher income, listening to radio broadcasts, and knowledge of blood donation were found to be the independent predictors of attitude. The practice of blood donation was higher among respondents who were older, attended certificate and above education, were knowledgeable, and had favorable attitude. The finding of this study also justified any possible interventions on the independent predictors. There should be a regularly scheduled awareness creation and voluntary blood donation campaigns organized at the community level to utilize potential donors who lack time and opportunity to donate blood.

\section{Acknowledgement}

We would like to express our heartfelt gratitude and sincere appreciations to all data Collectors and study participants in this study; without them this research wouldn't have been possible. We would like to extend our sincere appreciation to the dedicated staffs working in Debre Markos branch of the Ethiopian Blood Bank service as they have provided us the relevant data and information related to our research work. We would like to express our deeper thanks to Debre Markos University, college of Medicine and Health Sciences and Gamby Medical Sciences College for facilitating the research work. Finally, our gratitude also goes to Dr. Mohammed Seid and Sualih Mussa for English language and grammar corrections.

\section{Funding}

Not applicable.

\section{Availability of data and materials}

The dataset will not be shared in order to protect the participants' identities.

\section{Authors' contributions}

YAJ conceived and designed the study, performed analysis and interpretation of data and drafted the manuscript. AE and KYA supervised the design, conception, analysis, interpretation of data and made critical comments at each step of research. All authors read and approved the final manuscript.

\section{Competing interests}

The authors declare that they have no competing interests.

\section{Consent for publication}

Not applicable.

\section{Ethics approval and consent to participate}

The Study was reviewed and approved by the Ethical review committee of Debre Markos University, College of Medicine and Health Science. All participants were pre-informed of the aim of the study and their full right to withdraw or refuse to participate before their verbal consent was obtained.

\section{Author details}

${ }^{1}$ Community based newborn care officer, JSI/L10K Finote Selam, Ethiopia.

${ }^{2}$ School of medicine, College of Medicine and health science, Debre Markos University, PO Box: 269, Debre Markos, Ethiopia. ${ }^{3}$ Department of Public Health, College of Medicine and Health Science, Debre Markos University, PO Box: 269, Debre Markos, Ethiopia.

Received: 14 September 2015 Accepted: 23 August 2016

Published online: 05 September 2016

\section{References}

1. World Health Organization. WHO Global Data Base on Blood Safety, Summary Report. Geneva; 2011.

2. Blood safety and availability. [http://www.who.int/mediacentre/factsheets/ fs279/en/]. Accessed Jun. 2014

3. WHO African Region. Regional training workshop on blood donor recruitment: pre- and -post donation counseling. Addis Ababa; 2006.

4. World Health organization. Making Safe Blood Available in Africa, vol. Geneva: Statement by Coordinator; 2006.

5. Central Statistical Agency (CSA). The 2007 Population and Housing Census of Ethiopia. Addis Ababa: Statistical Summary Report; 2008.

6. Central Statistics Agency, ICF Macro Calverton. Ethiopia Demographic and Health Survey, vol. Addis Ababa: Final report; 2011.

7. Ethiopia: Road Traffic Accidents. [http://www.worldlifeexpectancy.com/ ethiopia-road-traffic-accidents]. Accessed Dec 2014.

8. Federal democratic republic of Ethiopia, Ministry of Health. National blood transfusion services strategy, vol. Strategy, Addis Ababa, Ethiopia. 2005.

9. Blood safety. [http://www.afro.who.int/en/ethiopia/country-programmes/ topics/4466-blood-safety.html]. Accessed Aug 2014.

10. National Blood Bank Service in Ethiopia. [http://www.moh.gov.et/nbbso] Accessed June 2014

11. Gebremeskel M, Girmatsion F, Lakew A, Zewda B, Mussie A. Intention to donate blood among the eligible population in Mekelle City, Northern Ethiopia: Using the theory of planned behavior. Am J Health Res. 2014;2(4):158-63.

12. Chalachew M, Meaza T, Andualem D, Megdelawit T, Tesfalem T, Hawult T. The level and associated factors of knowledge, attitude and practice of blood donation among health science students of Addis Ababa University. Int J Med Health Sci Res. 2014;1(10):105-18.

13. Shenga N, Thankappan K, Kartha C, Pal R. Analyzing socio demographic factors amongst blood donors. J Emerg Trauma Shock. 2010;3(1):21-5.

14. Balkees HA, Mohammad YNS. Investigating Knowledge and Attitudes of blood donors and barriers concerning blood donation in Jordan. Proc Soc Behav Sci. 2014;116:2146-54.

15. Benedict N, Usimenahon A, Alexander IN. Knowledge, Attitude and Practice of Voluntary Blood Donation among Healthcare Workers at the University of Benin Teaching Hospital, Benin City, Nigeria. J Blood Transfu. 2013;1-6.

16. Uma S, Arun R, Arumugam P. The Knowledge, Attitude and Practice towards Blood Donation among Voluntary Blood Donors in Chennai, India. J Clin Diagn Res. 2013;7(6):1043-6.

17. Benedict N, Usimenahon A, Alexander NI, Isi A. Knowledge, attitude and practice of voluntary blood donation among physicians in a tertiary health facility of a developing country, Benin City, Nigeria. Int J Blood Transfus Immunohematol. 2012:2:4-10.

18. Sanayaima DH, Jalina L, Shantibala K, Vijaya EL. Knowledge, Attitude and Practice (KAP) of Blood Safety and Donation. Ind Med Gaz. 2012;145(1):1-5.

19. Ahmed Z, Zafar M, Khan AA, Anjum MU, Siddique MA. Knowledge, attitude and practices about blood donation among undergraduate medical students in Karachi. J Infect Dis Ther. 2014;2:134.

20. Anju D, Atul S, Rahul C, Rajendra C. Knowledge, attitude and beliefs of people in North India regarding blood donation, Lucknow, India. Simti servizi srl. 2014;12(1):21-7.

21. Sabu KM, Remya A, Binu VS, Vivek R. Knowledge, Attitude and Practice on Blood Donation among Health Science Students in a University campus, South India. Online J Health Allied Scs. 2011;10(2):1-3.

22. Salaudeen AG, Musa OI, Awoyemi AO, Bolarinwa AO, Adegboye AO, Samuel SO. Community survey on blood donation practices in a northern state of Nigeria. J Prev Med Hyg. 2011;52:21-5.

23. Junu $\mathrm{H}$. A research report on knowledge, attitude and practice on blood donation among 18-25 years bachelor level people. Masters thesis. HOPE International College, Department of Public Health; 2008.

24. Mousavi F, Tavabi AA, Golestan B, Ammar-Saeedi E, Kashani H, Tabatabaei R, Iran-Pour E. Knowledge, attitude and practice towards blood donation in Iranian population. Transfus Med. 2011;21:308-17. 